As Scripps Institution of Oceanography (SIO) celebrates 100 years, its oldest research unit, the Marine Physical Laboratory (MPL), turns 57, still carrying on the tradition of leading innovation in seagoing, experiment-oriented efforts to unravel the secrets of the ocean and the subsea environment. The emphasis at MPL in the early years was on ocean acoustics and geophysics/geology. Though its research base has expanded to include physical and biological oceanography and atmospheric and ocean optics research, acoustics and signal processing still play a central role as subjects of research and as methods of ocean exploration and imaging. Over more than a half century of existence, the emphasis at MPL is still on ocean observation and exploratory research with the parallel development of unique technology to carry out this research.

\section{The Early Years}

MPL's roots go back to 1941 when, faced with large-scale destruction of ships by submarines in World War II, the nation mobilized the scientific community to learn how to defend against this threat. Three university-operated laboratories were thus established: Columbia University Division of War Research, Harvard Underwater Sound Laboratory, and University of California Division of War Research (UCDWR). UCDWR was led initially by Vern Knudsen of the University of California, Los Angeles, with senior staff recruited from academic institutions across the country.

Given the primitive initial knowledge of the ocean, and of the technology for dealing with its problems, there was immediate progress as this new flood of activity built up. By the end of the war, there were effective new sonar systems and the beginnings of understanding the environment, but there were also new questions about the nature of the ocean and the seafloor and a vision of how to create even more effective detection systems.

While many academics returned to their home universities at the close of the war, a few leaders had become interested in the challenges and opportunities they could see ahead. At the same time, some in the Navy realized the academic research potential that had been tapped and decided to support academic groups in parallel with the maintenance of a much larger inhouse research establishment than that which had existed before the war. Both the academic and Navy communities were motivated by the probability that the USSR would, as they did, initiate an energetic development of submarine capabilities built on technology and personnel drawn from Germany.

The key scientist at this point was Carl Eckart, an eminent theoretical physicist who had come from the University of Chicago to head the theoretical efforts of UCDWR (Figure 1). Eckart directed UCDWR during its closing days, editing the laboratory's final report, which ably summarized the newly gained knowledge while noting the underwater-acoustics challenges that lay ahead (Eckart, 1946).

Most of the UCDWR personnel and their programs were taken over by the newly formed Navy Electronics Laboratory, but Eckart foresaw the essential role that a small parallel academic unit could play and was personally interested in many of the newly opening vistas. This view was shared by Roger Revelle, then still on active duty as an officer in the sonar development component of the Navy's Bureau of Ships. The result was an exchange of letters between the chief of the bureau ${ }^{1}$ and the president of the University of California, ${ }^{2}$ which led directly to the establishment of MPL in mid1946 as a research unit of the university with a subsequent allocation of three tenured faculty billets. The Navy provided space and facilities in the Navy Electronics Laboratory on Point Loma, facing San Diego Bay.

Eckart had a multifaceted vision for the laboratory. He realized that studies of sound in the sea really meant a study of the ocean environment and could thus produce not only new sonar systems but also new understanding of the environment itself. This led to his bringing Russell Raitt with him from UCDWR. Raitt was a geophysicist interested in using acoustics to understand the nature of the earth's crust as viewed from an oceanic perspective. Eckart also had become fascinated with immediate challenges that wartime work had raised, focusing on two emerging problems. One was the question of the anomalously high sound 


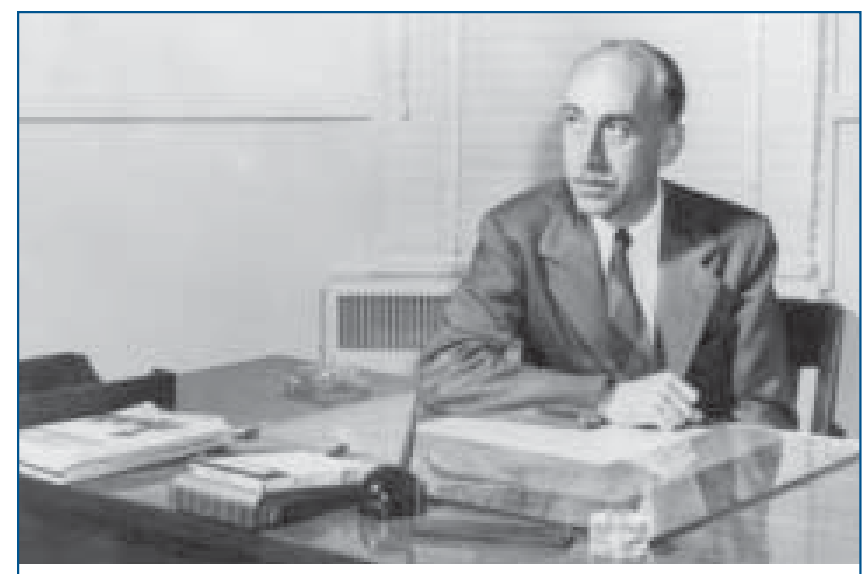

Figure 1. Carl Eckart was the first director of MPL, which had grown out of the University of California Division of War Research.

absorption that had been measured at sea in wartime studies of sound transmission. This led him to recruit Leonard Liebermann, a physicist who had been a member of the wartime effort at Woods Hole Oceanographic Institution, who was interested in unraveling the interactions between sound waves and molecular-level physical/chemical processes. Eckart's other question was how best to detect signals in the presence of noise. Within this context, his own work played a significant role in the birth of the field of signal processing.

Overarching these research threads were two guiding operating principles: to devise innovative experimental approaches to problems and to involve students in the resulting research. Eckart recruited two more experimentalists-Phillip Rudnick and Fred Spiess-as well as a number of short-term visiting physicists from other institutions. Graduate students were involved in the program from its inception in spite of the complexities of working through the distant Physics Department at UCLA.

After less than two years as MPL director, Eckart's attention was spread further abroad as he took on the directorship of Scripps Institution of Oceanography from 1948 to 1950. During that period he shifted MPL from the direct administration of the UC headquarters to a division of SIO, as it has remained ever since. In 1952 Eckart left for a sabbatical year at the Institute for Advanced Study at Princeton University. Upon his return to Scripps he decided not to continue as MPL director and was replaced by Sir Charles Wright, who had retired to Canada after a career that included directorship of the Royal Navy Scientific Service. After serving from 1952 to 1955 Sir Charles retired and was replaced by Alfred B. Focke, a Navy Electronics Laboratory group leader and chief scientist for the nuclear depth-charge test, Operation Wigwam. In 1957 Focke moved on to be chief scientist at Point Mugu
Naval Missile Test Center. Spiess was appointed director in 1958. At that time, also, primary sponsorship of MPL was transferred from the Navy's Bureau of Ships to the Office of Naval Research (ONR) and the supporting research equipment that had been provided by the Navy Electronics Laboratory was transferred to the university.

MPL's scientific and engineering staff grew during the 1950s, but primarily through strengthening the initial threads. George Shor joined Raitt's group and through successive expeditions they developed seismic refraction capabilities to map the structure of the crust beneath the deep ocean. The results generated a picture of the Pacific Basin that showed a crust much thinner than that of the continents and revealed the surprising fact that the quantity of sediment expected from millennia of continental erosion was not there. This was one of the phenomena that forced the acceptance of the plate tectonics concept, explaining that as old crust was subducted at plate boundaries, the accumulated sediment was cycled onto and underneath the overriding plates.

On the signal-processing front, theoretical concepts quickly outran hardware capabilities of the analog world and vacuum-tube computers. At MPL there were imaginative efforts to build new devices, particularly by Rudnick and Victor C. Anderson, a group leader who had been an MPL graduate student. Anderson was quick to see the opening provided by representing the sonar signal by a close-spaced series of polarity samples, resulting in the beginnings of digital-signal processing-a major advance that provided the base for experimental sonar installations, soon put to use in Navy operational systems. The first of these was the delay line time compressor (DELTIC; Anderson, 1955), a system in which a simple digitized version of an acoustic signal could be repetitively and rapidly played back as the basis for making fine-scale correlation or frequency analyses over wide frequency bands in real time. The second was digital multibeam steering (DIMUS; Anderson, 1957) with which the outputs from an array of independent sound receivers (hydrophones) could be combined to provide simultaneous parallel outputs focused in many different spatial directions. These techniques led to rethinking of the nature of submarine sonar systems (Anderson and Spiess, 1959).

While these two main lines of investigation were the primary concerns, there were others leading to the gradual broadening of the scope of MPL's activities to other aspects of experimental physics at sea and in the laboratory. Fred Fisher, who completed his University of Washington Ph.D. thesis with work conducted at MPL, expanded Liebermann's work on sound absorption. Spiess devised and demonstrated a submarine tactical communication system and collaborated with UCLA scientists in a program of measuring gravity at sea; Liebermann developed and applied a new technique for measuring fine-scale inhomogeneities in the 


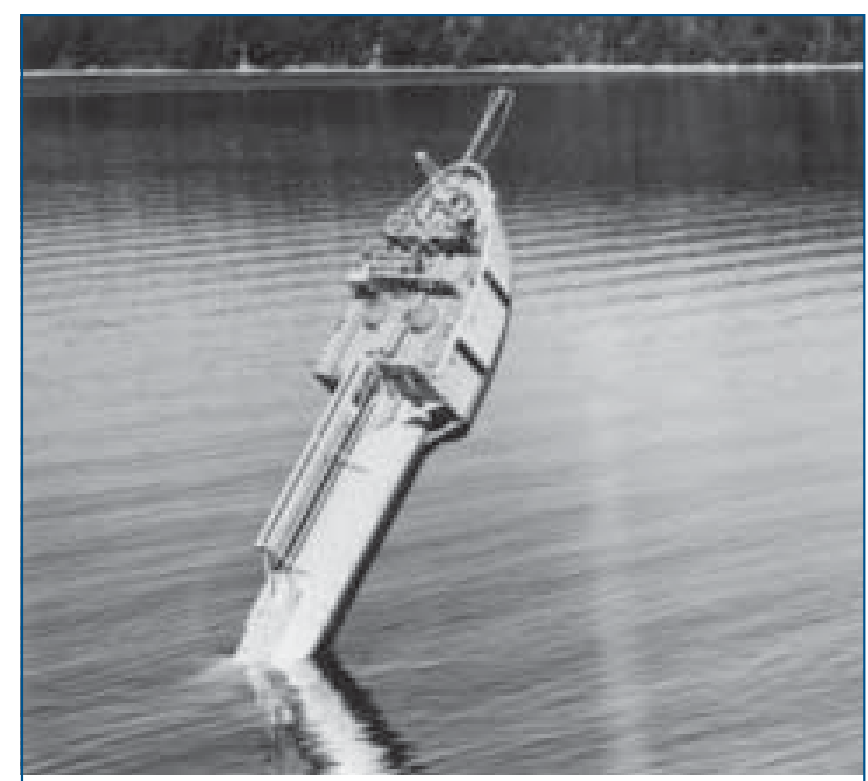

Figure 2. FLIP returning to horizontal position during initial trials conducted at Dabob Bay in the Hood Canal, Washington.

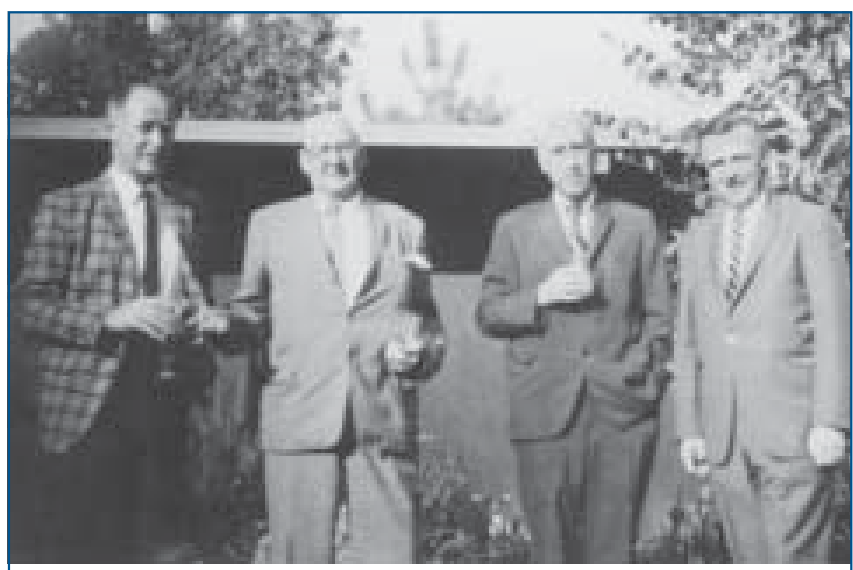

Figure 3. The early directors of the Marine Physical Laboratory in April 1968. Left to right: Fred Spiess, Charles S. Wright, Carl Eckart, and Alfred Focke.

ocean; and Rudnick collaborated with other SIO scientists investigating radio-wave propagation in the ocean.

One nonacoustic effort began with Sir Charles's interest in geomagnetism. On the 1952 Capricorn Expedition, Ron Mason had used a ship-towed magnetometer adapted from a World War II airborne system by Jeff Frautschy and others at Scripps. Sir Charles was aware that the U.S. Coast and Geodetic Survey was being tasked to make a dense seafloor topographic survey off the West Coast of the United States and helped arrange it so that Mason could tow the magnetometer from the survey ship and that MPL would provide the necessary engineering support, which was led by Arthur Raff who had previously been part of Raitt's group. The result was the famous magnetic anomaly map (Mason and Raff, 1961; Raff and Mason, 1961) demonstrating the existence of bands of anomalously high and low magnetization having continuity over hundreds of miles-the fundamental building blocks of seafloor spreading and its successor plate tectonics. Subsequently, Victor Vacquier, who had devised the airborne flux gate magnetometer (Vacquier, 1945) joined MPL and, refining the more robust proton precession magnetometer approach, expanded MPL's seagoing geomagnetic research program.

One other activity of importance was the involvement of senior staff members (particularly Spiess and Anderson) in various Navy research advisory committees and workshops that were instituted to maintain fruitful interactions between the science and Navy operational communities. This produced numerous dividends in motivating new research directions and generating multi-institution collaborative programs

\section{The 1960s: The Golden Era of Growth}

The 1960s saw the fruition of the initial building period. MPL had established a senior scientific group of nine (Anderson, Raitt, Shor, Fisher, Liebermann, Spiess, Rudnick, Vacquier, and Eckart), along with a strong engineering staff and an administrative structure that could support major equipment construction and seagoing operations. ONR remained the primary source of support, augmented by other Navy programs. There were fruitful collaborations both ashore and at sea with others at Scripps.

MPL continued to emphasize two essential elements: innovations typical of experimental physics, and seagoing action to learn about the real ocean and the crust beneath it. Some of the principal devices that emerged were

- FLIP, an easily deployable manned spar buoy laboratory (Fisher and Spiess, 1963; Figure 2),

- RUM, a manipulator-equipped remotely operated seafloor tractor (Anderson, 1960),

- ORB, a support barge from which systems such as RUM could be operated (Anderson and Gibson, 1970),

- Deep Tow, a deep seafloor imaging and mapping system (Spiess and Tyce, 1973),

- acoustic transponder navigation (Spiess et al., 1966), and

- Albacore DIMUS, a 256-hydrophone receiving array with a processor generating a comparable number of focused outputs installed in an experimental U.S. submarine (Anderson and Gibson, 1960).

While the decade of the 1960s was a golden era for oceanographic facility development, at the same time there were changes in the surrounding environment (Figure 3). The University of California began building a general campus adjacent to SIO. Liebermann and 
Eckart moved into the new Physics Department, Eckart became a vice chancellor, and Anderson began to play a role in electrical engineering, particularly in acoustics. Spiess served as director of Scripps and then as an associate director.

As opportunities to use these new tools appeared, adventurous graduate students joined in, becoming a larger component of the laboratory's program. Although the senior staff did not grow significantly during this period, there were visiting scientists who joined MPL for periods of up to several years, including the beginning of a sequence of postdoctoral appointees, mostly from Cambridge University.

Most of these technological advances were carried out in the early 1960s and scientific and engineering results flowed even from their initial trial operations. Deep Tow data contributed to the evidence supporting the emerging plate tectonics concept; FLIP supported sound propagation studies and initial internal wave investigations.

Continuing to build on earlier work, Anderson led the signal processing component of Project Artemis, a major multilaboratory program to investigate the possibilities of ocean basin-scale active sonar systems for submarine detection. He also led a program of installation and testing of the DIMUS concept on a number of Navy ships and submarines. Fisher and Spiess developed programs to understand the distortions that acoustic signals are subjected to as they travel through the water and interact with the seafloor. Vacquier added seafloor heat-flow measurement capability to his already active geomagnetic seagoing activities, while Raitt and Shor improved seismic reflection and refraction techniques.

Such evolution continued in the 1970s. After 25 years, MPL was changing in many ways. With the development of marine geophysics based on Raitt and Shor's seismic methods, the Spiess Deep Tow system and Vacquier's group's geomagnetic and heat flow interests, the National Science Foundation became a major element in the laboratory's support. Most important, a second generation of senior staff members emerged.

There was further diversification growing out of these new capabilities and expanding the nature of existing activities. Rob Pinkel completed his Ph.D. using FLIP as a base for studying internal waves and joined the staff, introducing a physical oceanography component. This program quickly drew on acoustic technology as Pinkel developed a FLIP-mounted Doppler sonar approach to observing the dynamics of the upper ocean, finding a much more complex environment than could be seen with prior instrumentation. Peter Lonsdale, after completing his degree using the Deep Tow system to study seafloor morphology, joined the staff, bringing geology into the fold. The Deep Tow system was very active, averaging about three expeditions per year under the leadership of Spiess, Lonsdale, John Mudie, and Kenneth Macdonald. Activity ranged from searching for lost equipment to manganese-nodule research to the discovery of hydrothermal vents at the crest of the Galapagos Spreading Center. Vacquier's group continued its geomagnetic investigations while the heat-flow portion of his group, augmented during this period by John Sclater, documented spatial variations in the heat-flow field in relation to seafloor spreading.

FLIP was used by Fisher's group and Gerald Morris for a variety of underwater acoustic investigations documenting the nature of the ambient noise field and various propagation phenomena. Special tools were developed from these studies, including vertical arrays of hydrophones that could be positioned at interesting depths throughout the water column, and a 48-element array mounted on the bottom (aft) end of FLIP. The 48-element array was only one of the several DIMUS-based research arrays built by Anderson's group. Two larger systems were assembled, each in its own submersible barge-like structure operating suspended below ORB to provide highangular-resolution observations of scattering and ambient noise as well as exploring the limits on array size. William Hodgkiss was recruited in the signal processing arena, creating a more physics-oriented perspective to complement Anderson's hardware orientation and Hodgkiss began to be involved with the FLIP-based acoustics program.

\section{Transition Years}

Kenneth Watson, a theoretical plasma physicist from Berkeley, assumed directorship of MPL in 1981, leading the lab for the next twelve years. While the thrust of the lab remained unchanged, the scope was broadened. Theoreticians Henry Abarbanel (nonlinear physics), Mike Buckingham (acoustics), and Bill Young (oceanography as a postdoc) joined the laboratory during this period. Jerry Smith joined Pinkel's Ocean Physics group, with a focus on extending acoustic Doppler techniques to the study of Langmuir cells, ocean surface waves, and air-sea momentum exchange. Grant Deane, an Oxford plasma physicist and SIO Mellon Fellow, initiated programs in nearshore and near-surface acoustics. John Hildebrand came fresh from his Stanford Ph.D. in acoustic microscopy to post-doc in the Deep Tow group. He quickly developed an independent, active and continuing program in marine geophysics. Chris de Moustier, a Scripps graduate, branched out from his efforts with Deep Tow to develop shipboard multibeam swath mapping systems. Working with a variety 


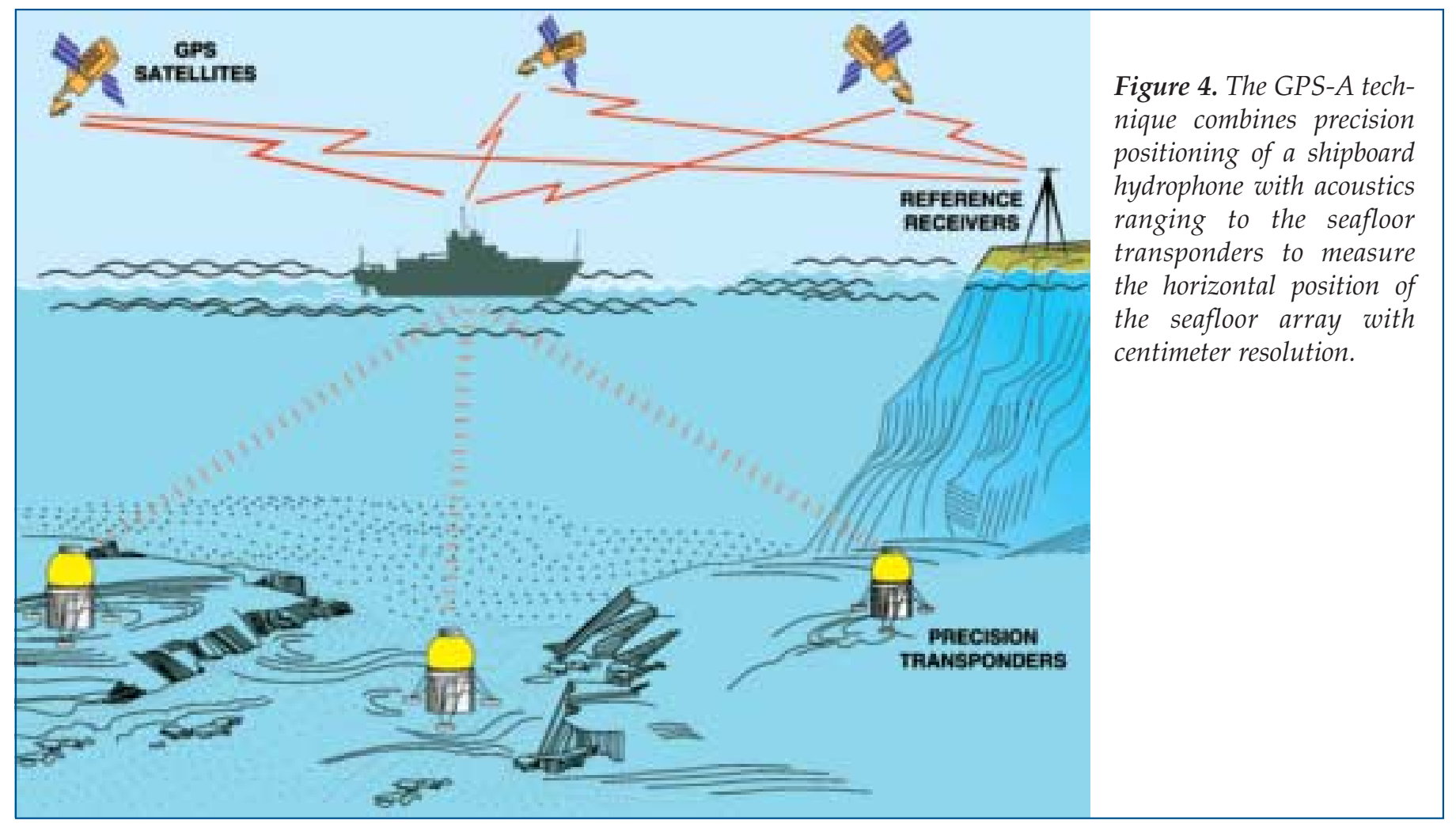

of manufacturers, he brought Scripps into a leadership position in this newly emerging field. Another SIO graduate, Spahr Webb, was recruited from the East Coast. At MPL, Spahr extended his experimental program to span the fields of acoustics, seismology, and physical oceanography. Jules Jaffe also joined the laboratory, adding an active program in bioacoustics and optics to the mix of MPL activities. Finally, Ken Melville was recruited from the Massachusetts Institute of Technology to pursue field, laboratory, and theoretical studies of air-sea interaction, gas exchange, and nonlinear wave propagation.

The texture of the laboratory changed considerably with this diversification. In 1993, William Kuperman, a senior scientist from the Naval Research Laboratory, became the director of MPL.

\section{MPL Today and Tomorrow}

With a firm foundation in ocean science and technology, during the last quarter century MPL has expanded into many areas of ocean science, including geology and geophysics, physical and biological oceanography, atmospheric and ocean optics, and new vistas in acoustics and signal processing. The overriding, infectious research culture at MPL is that of interdisciplinary, observational ocean science. What follows is an overview of the basic research areas at MPL today.

\section{Geophysics and Geology}

Within geophysics and geology, Lonsdale (1994, 1995) maps the seafloor, extracting the history of plate motions from the details of seafloor shape and the magnetic field evidence imbedded therein. His research has concentrated on using advanced acoustic systems, some of them developed in-house (e.g., Deep Tow), for exploration and study of active deep-sea environments.

De Moustier, now at the University of New Hampshire, has been involved in all aspects of swath mapping development and use (Gallaudet and de Moustier, 2001; Stemlicht and de Moustier, 2002). He has used his expertise in sonar engineering and signal processing to make quantitative measurements of seafloor scattering and its relation to surficial structure. In recent years, David Chadwell (Chadwell and Bock, 2001; Chadwell et al., 1999) has extended high-precision survey techniques to include points on the seafloor, where the earth's most active plate boundaries are located. He is developing a new field of oceanography by including these seafloor benchmarks, which allow real-time, direct measurement of oceanic plate motion (Figure 4).

LeRoy Dorman (Gilbert et al., 2001; Smith et al., 2001) uses ocean-bottom seismographs to study the seismic structure of oceanic spreading centers and other parts of the ocean basins. His research with ocean seismic arrays has revealed details of the propagation of seafloor seismic noise and extending to land arrays, he has provided remarkable improvements in the location and depth of subduction zone earthquakes.

Webb (1998), who is now at Lamont-Columbia, combining physical oceanography and solid-earth 


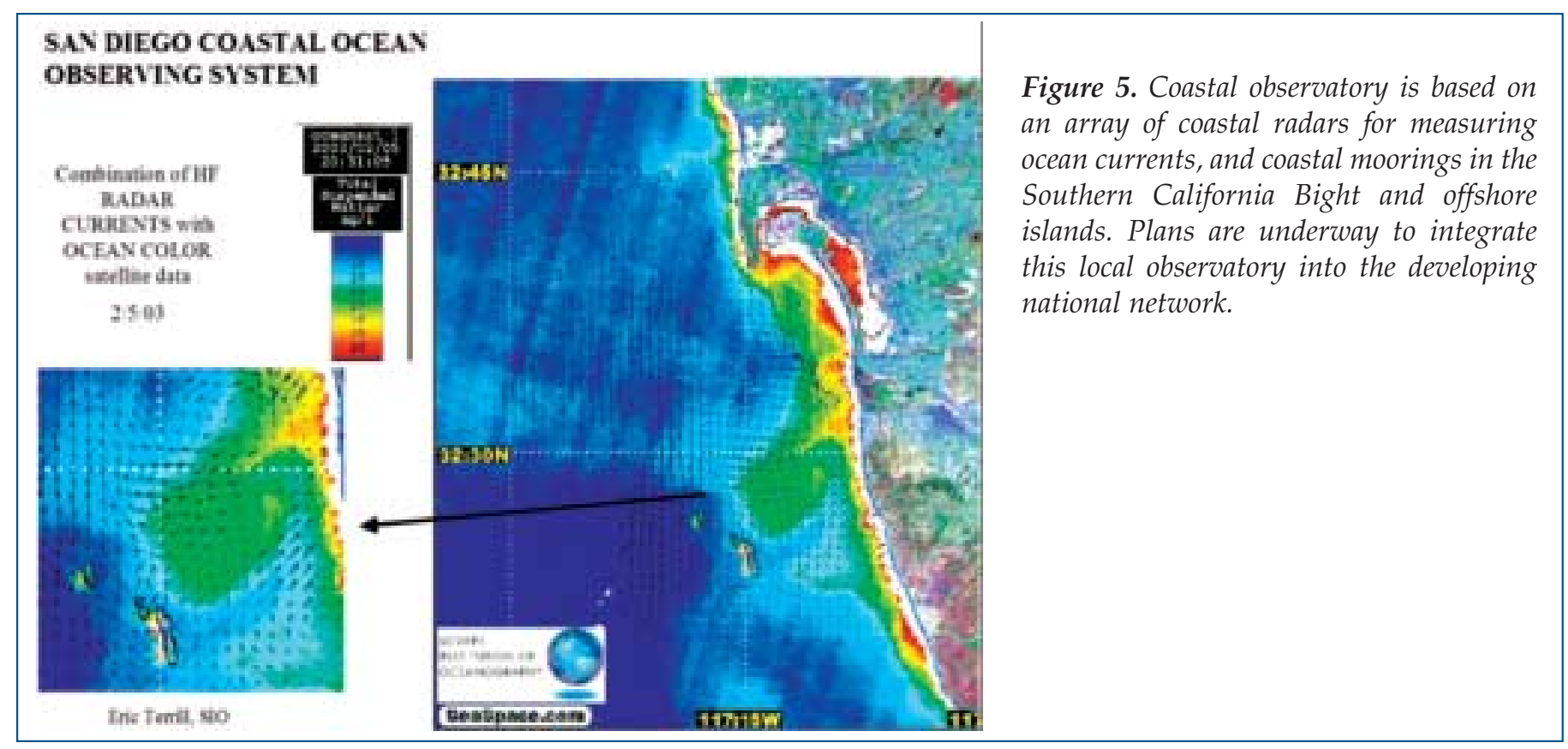

geophysics, has provided insight into the excitation of seismic noise by ocean waves. Much of this work has been done using instruments of his own design.

Hildebrand (Crawford et al., 1999; Sohn et al., 1999) has exploited MPL's expertise in deeply towed sensors to explore details of acoustic and magnetic signatures of geophysical phenomena such as seafloor compliance and earthquakes. He has developed passive and active seismic tomography techniques and has designed and operated hydrophone arrays in acoustic propagation experiments. The expertise of Hildebrand's group has most recently migrated to marine mammal research (McDonald et al., 1995; Wiggins, in press).

\section{Physical and Biological Oceanography}

Within physical and biological oceanography at MPL, Melville (1996; Melville and Matusov, 2002) is a specialist in nonlinear waves, air-sea interaction, deepwater breaking waves, Langmuir circulations, and gas exchange. He has pioneered radar, video, and acoustic observations at the air-sea interface.

Watson has contributed to the study of nonlinear interactions among ocean surface waves and internal waves, as well as the interaction between surface and internal waves.

Eric Terrill (2002; Terrill et al., 2001) is a graduate of the Scripps Applied Ocean Science program. He is studying the dynamics of coastal currents off San Diego and is the leader of the CODAR (coastal ocean dynamics applications radar) monitoring program at Scripps. He has been spearheading an effort to develop and apply the latest ocean observing technologies to form a network as part of the San Diego Coastal Ocean Observing System (Figure 5 ).
Jaffe develops acoustical and optical imaging systems for the study of zooplankton and phytoplankton in the sea (Jaffe et al., 1998). Among his accomplishments is the development of an infrared camera system for remote assessment of the health of coral reefs.

Darius Stramski uses optical techniques to study the upper ocean (Stramski et al., 1999; Stramski et al., 2001). He is improving algorithms for the study of phytoplankton and microbial populations from spacebased sensors, as well as the mapping of the global carbon budget (Figure 6).

Deane and Dale Stokes have developed a number of new instruments, including an optical instrument to measure the numbers and sizes of bubbles inside breaking-wave crests, and a method for deploying large numbers of pressure and temperature sensors in the nearshore region (Dean and Stokes, 2002). Using this kind of instrumentation, they have been able to elucidate some of the fundamental physical principles controlling air enterainment in breaking waves and breaking surf, and the impact of breaking waves on airsea gas exchange.

Smith (1998; Smith and Largier, 1995) specializes in the acoustic measurement of ocean surface waves and Langmuir circulations. Working from FLIP, he has made pioneering measurements of the evolution of Langmuir circulations and the momentum transport from wind to waves.

Pinkel (2000; Pinkel and Smith, 1992) is studying the cascade of internal-wave energy from large to small vertical scales and the development of ocean turbulence. He works from FLIP, conventional ships, and Arctic ice camps.

Gerald D'Spain and Aaron Thode track whales by using the latest research in matched field acoustics 


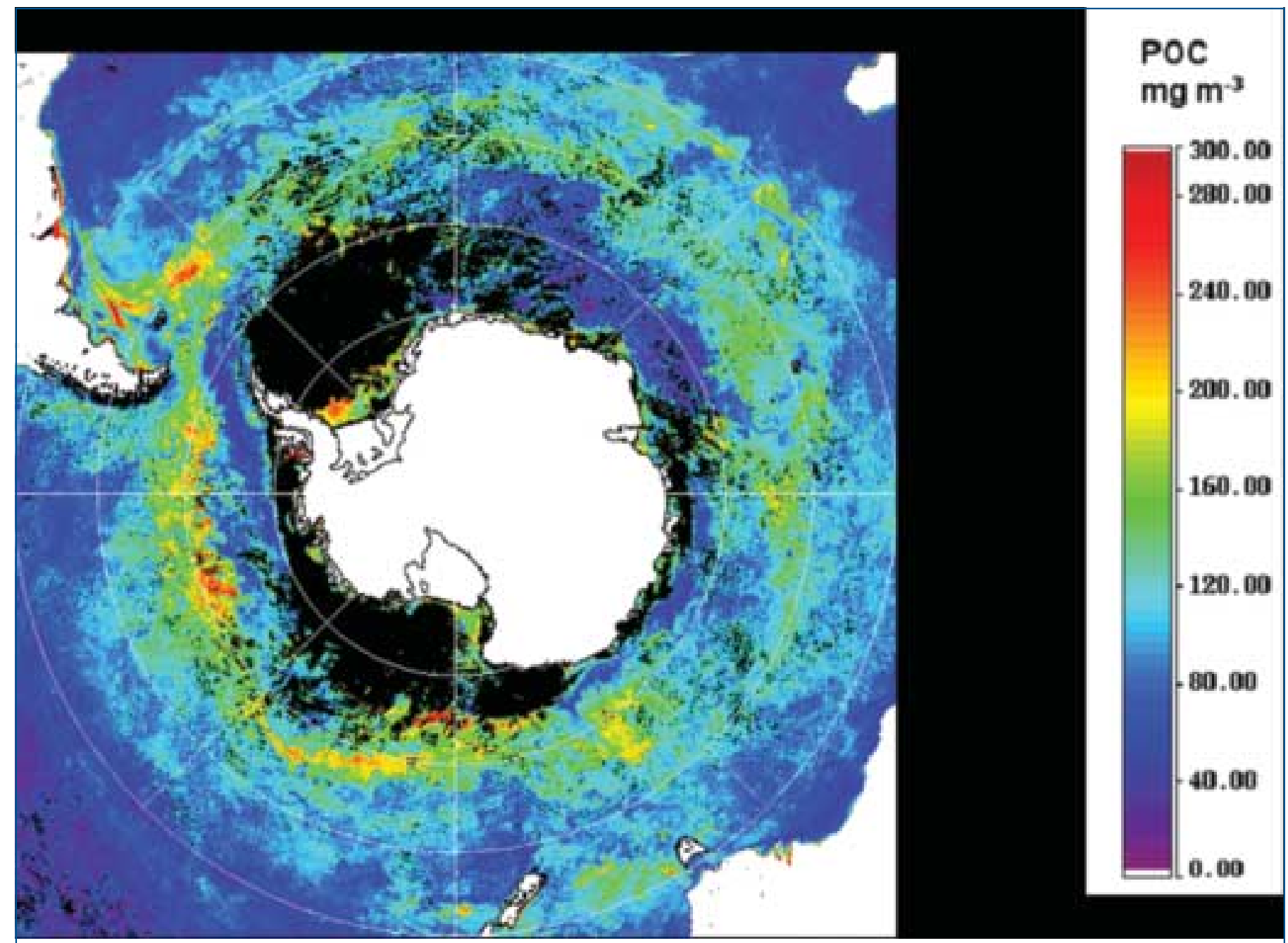

Figure 6. A new algorithm was applied to satellite imagery of the Southern Ocean from the SeaWiFS sensor deployed on OrbView-2 satellite to generate, for the first time ever, maps depicting large-scale distributions of particulate organic carbon (POC) in the ocean. Image reveals a zonal band of elevated POC that develops during the austral summer around Antarctica.

(Thode et al., 2000; Thode et al., submitted). Among other accomplishments they have used whale sounds to invert the geoacoustic properties of the ocean environment.

Dale Stokes works on the development and fabrication of new environmental sensors to help study marine physical and biological questions (Stokes et al., 2002; Stokes, et al., in press). In a novel twist, he and Grant Deane are using naturally occurring bioluminescent plankton as microscopic "sensors" responsive to fluid shear stress to study the turbulence generated by breaking ocean waves. Stokes's new sensing technology goals are aimed at trying to understand the coupling between the physical environment and the mesoscale distribution of marine organisms.

\section{Atmospheric and Ocean Optics}

Several groups are working in atmospheric and ocean optics within MPL. Janet Shields specializes in characterizing and understanding the atmosphere and its properties. Her group is best known for development of digital autonomous Whole Sky Imagers that acquire cloud and sky data continuously, from daylight through starlight conditions.

Dariusz Stramski's Ocean Optics group is working to establish the scientific basis for understanding the variability in ocean optical properties and light fields within and leaving the ocean; this research involves predicting ocean optical properties given the types and concentrations of particles suspended in seawater; and retrieving the optical properties and concentrations of optically significant constituents of seawater from satellite observations of ocean color. A significant recent accomplishment is development of satellite capability for determining the particulate organic carbon level in the ocean from remote sensing of ocean color.

Andrew Dickson investigates the chemistry of carbon dioxide in seawater (DelVallis and Dickson, 1998; 
Dickson et al., 2003). His projects include the improvement of techniques for measuring carbon dioxide parameters in seawater and a detailed study of the chemistry of acid-base processes in seawater.

Jaffe's Underwater Optical Imaging group specializes in inventing new technology for viewing the underwater marine environment using light. Recent projects were the creation of L-Bath, a three-dimensional, laser-based imaging system for measuring seafloor microbathymetry, and the FIDO- $\Phi$ system, an autonomous profiler that has recently yielded the first views of the underwater fluorescent microstructure of phytoplankton.

\section{Acoustics and Signal Processing}

MPL research in acoustics includes signal processing, acoustical physics, and acoustical oceanography. Buckingham's group was the first to introduce and implement the idea of acoustic daylight imaging, which is analogous to conventional photography, with ambient noise replacing daylight as the source of "illumination." Bubble acoustics and volcano acoustics have also been active areas for his research group (Buckingham, 2000; Buckingham et al., 2002).

Grant Deane has been active in studying nearshore acoustics, including underwater ambient noise generation, sound propagation through the surf zone, and the performance of underwater sonar and underwater communications systems.

Hildebrand has studied long-range acoustic propagation with one of the largest vertical acoustic arrays ever deployed, an extension of some earlier developments by Bob Tyce.

D'Spain has conducted extensive research measuring ocean acoustic fields with vector sensors for the purpose of understanding the physical structure of acoustic energy fluxes (D'Spain et al., 1991; D'Spain and Kuperman, 1999). He has worked on nearshore acoustics as well as long-range propagation that might affect the Nuclear Test-Ban Treaty. Hee-Chun Song has emphasized research on acoustic signal processing methods that are robust to ocean environmental mismatch (Song et al., 1998; Song et al., 2003). He has also worked on understanding scattering fields in the context of time-reversal acoustics.

Peter Gerstoft (1994; Gerstoft et al., 2003) works in the areas of geoacoustic inversion by global optimization methods, seismoacoustics, and long-range acoustic propagation as it impacts the Nuclear TestBan Treaty. He has also applied his acoustic expertise in match field processing to near-ocean surface radar propagation, utilizing clutter returns to estimate atmospheric conditions.

Bill Hodgkiss devotes much of his time to experimental ocean acoustics and signal processing, adaptive array processing, environmental parameter inversions, time-evolving spatial distribution of ambient ocean noise, and acoustic communications (Booth et al., 2000;

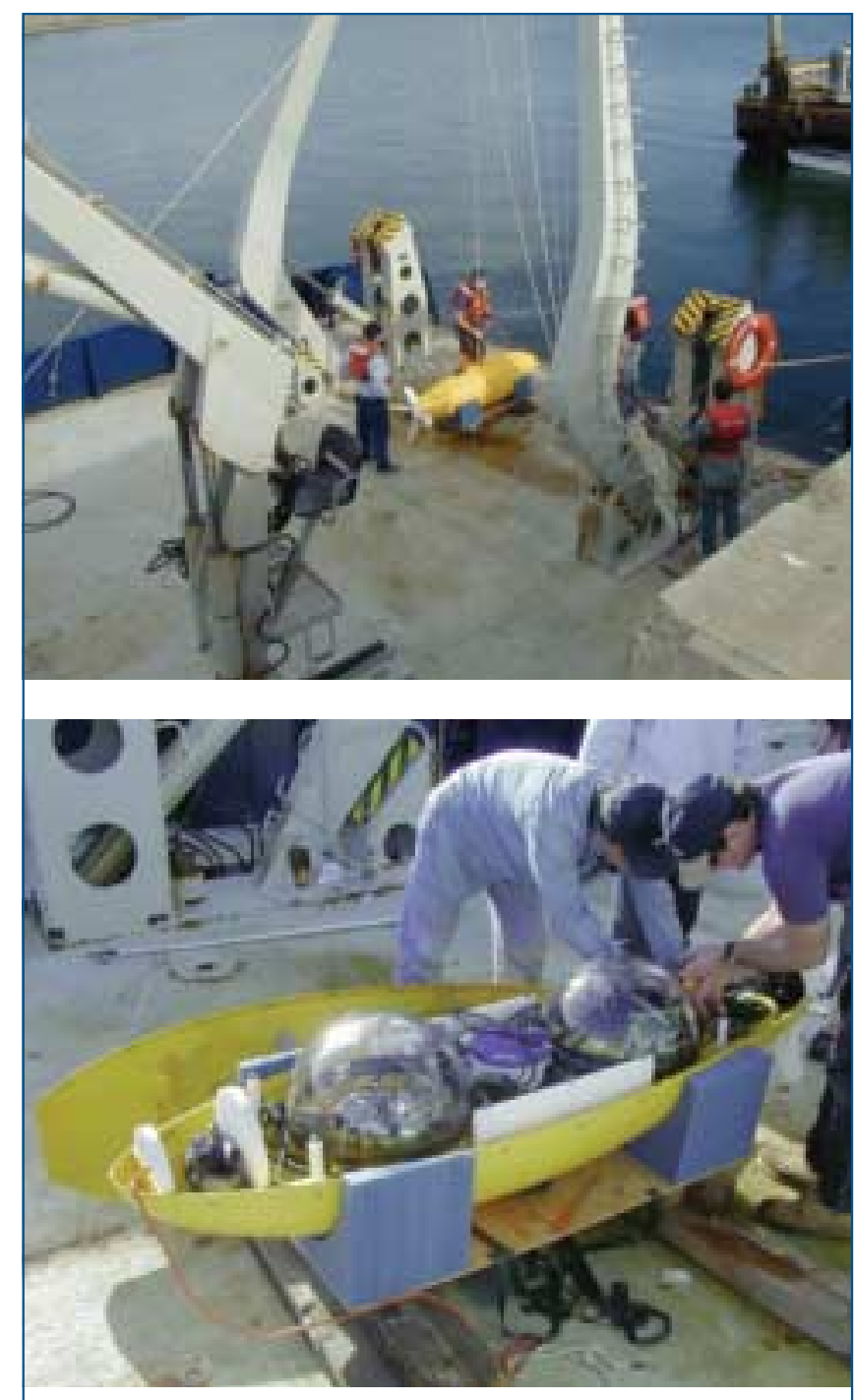

Figures $7 a$ and $7 b$. MPL's autonomous underwater vehicle is being prepared for ocean measurements associated with a passive acoustic synthetic aperture experiment.

Gerstoft et al., 2003). He and Kuperman were the first to implement a time-reversal mirror in the ocean.

Kuperman's research has been in experimental ocean acoustics and signal processing, propagation modeling, scattering theory, noise theory, and experimental and nonlinear acoustics (Kuperman et al., 1998). He is also coauthor of the textbook Computational Ocean Acoustics (Jensen et al., 1993).

\section{Emerging Technology and MPL's \\ Newer Scientific Facilities}

Almost all the research described above involved the development of unique ocean experimental equipment that was designed, constructed, and deployed by MPL scientists. Besides these individual group projects supporting their own research programs, MPL has also been active in supporting and making technology available to the broader ocean science community. 
Examples include Speiss's Deep Tow facilities; de Moustier's broad work in supporting ocean-mapping systems on oceanographic vessels; Pinkel's ocean sensing sonar; D'Spain, David Chadwell, Sean Wiggins, and Richard Zimmerman's Autonomous Underwater Vehicle group (Figures $7 \mathrm{a}$ and $7 \mathrm{~b}$ ); Eric Terrill's nearshore monitoring facility; and Philippe Roux's ultrasonics laboratory for modeling ocean acoustics.

\section{MPL Tomorrow}

MPL currently pursues basic observational ocean science by a combination of in situ measurements and remote sensing. In both cases, new instrumentation will be developed to confirm and/or extend theoretical understanding of ocean processes or in the case of acoustics, processes in the ocean. Future goals will be to strengthen our capability to perform electromagnetic remote sensing of the ocean surface and to increase the study and use of biological processes vis-à-vis instrumention development, remote sensing, and ocean exploration.

The latest addition of young research scientists to MPL already ensures that we are on the path of achieving some of our future goals while further strengthening ongoing programs. Future additions in growth areas will further ensure our continuing vitality.

\section{References}

Anderson, V.C., 1955: Sonar signal detection using a quartz delay line as a time compressor. USN J. Und. Acoust., 5, 3545.

Anderson, V.C., 1957: Digital multi-beam steering (DIMUS). [MPL TM-105, Marine Physical Laboratory, Scripps Institution of Oceanography].

Anderson, V.C., 1960: MPL experimental RUM. [Ref. 60-26, Scripps Institution of Oceanography, $\mathrm{UCSD}]$.

Anderson, V.C. and D.K. Gibson, 1960: Albacore DIMUS workbook. [Marine Physical Laboratory, Scripps Institution of Oceanography, UCSD].

Anderson, V. C. and D.K. Gibson, 1970: ORB-RUM operations January 27-30. [Ref. 70-13,Scripps Institution of Oceanography, UCSD].

Anderson, V.C., and F.N. Spiess, 1959: Syncretic submarine sonar. USN J. Und. Acoust., 9, 217-222.

Booth, N.O., A.T. Abawi, P.W. Schey and W.S. Hodgkiss, 2000: Detectability of low-levelbroadband signals using adaptive matched-field processing with vertical aperture arrays. IEEE J. Oceanic Engr., 25(3), 296-313.

Buckingham, M.J., 2000: Wave propagation, stress relaxation, and grain-to-grain shearing in saturated, unconsolidated marine sediments. J. Acoust. Soc. Am., 108(6), 2796-2815.

Buckingham, M.J., E.M. Giddens, J.B. Pompa, F. Simonet and T.R. Hahn, 2002: Sound from alight aircraft for underwater acoustics experiments. Acta Acustica United with Acustica, 88(5), 752-755.

Chadwell, C.D. and Y. Bock, (2001): Direct estimation of absolute precipitable water in oceanicregions by GPS tracking of a coastal buoy. Geophys. Res. Let., 28(19), 3701-3704.

Chadwell, C.D., J.A. Hildebrand, F.N. Spiess, J.L. Morton, W.R. Normark and C.A. Reiss,(1999): No spreading across the southern Juan de Fuca Ridge axial cleft during1994-1996. Geophys. Res. Let., 26(16), 2525-2528.

Crawford, W.C., Webb, S.C. and J.A. Hildebrand, 1999: Constraints on melt in the lower crustand Moho at the East Pacific Rise, 9 degrees 48' N, using seafloor compliance measurements. J. Geophys. Res., 104(NB2), 2923-2939.

Dean, G.B. and M.S. Stokes, 2002: Scale dependence of bubble creation mechanisms in breaking waves. Nature, 418(22), 839-844.

DelVallis, T.A. and Dickson, A.G., 1998: The pH of buffers based on 2-amino-2-hydroxymethyl-1,3propanediol ("tris") in synthetic sea water. DeepSea Res., I 45, 1541-1554.

Dickson, A.G., Afghan, J. D. and Anderson, G.C., 2003: Reference materials for oceanic $\mathrm{CO}_{2}$ analysis: A method for the certification of total alkalinity. Mar. Chem., 80,185-197.

D'Spain, G.L. and W.A. Kuperman, 1999: Application of waveguide invariants to analysis of spectrograms from shallow water environments that vary in range and azimuth. J. Acoust. Soc. Am. 106(5), 2454-2468.

D'Spain, G.L., W.S. Hodgkiss and G.L. Edmonds, 1991: Energetics of the deep ocean's infrasonic sound field. J. Acoust. Soc. Am., 89(3), 1134-1158.

Eckart, C., 1946: Principles of Underwater Sound. [Summary Technical Report of NDRC Div. 6,v. 7, Washington, DC. Reprinted by the U.S. Department of Navy, Headquarters Naval Material Command, Washington, DC 20360, 1968].

Fisher, F.H. and F.N. Spiess, 1963: FLIP-Floating instrument platform. J. Acoust. Soc. Am.35(10), 1633-1644.

Gallaudet, T.C. and C.P. de Moustier, C.P., 2001: Corrections to "on optimal shading for arrays of irregularly-spaced or noncoplanar elements." IEEE J. Oceanic Eng., 26(3), 416-419.

Gerstoft, P., 1994: Inversion of seismo-acoustic data using genetic algorithms and a posteriori probability distributions. J. Acoust. Soc. Am., 95, 770-782..

Gerstoft, P., L.T. Rogers, J.F. Krolik and W.S. Hodgkiss, 2003: Inversion for refractivity parameters from radar sea clutter. Radio Science, 38(3), 1-22.

Gilbert, H.J., A.F. Sheehan, D.A.Wiens, K.G. Dueker, L.M. Dorman, J. Hildebrand, J. and W.Spahr, 2001: Upper mantle discontinuity structure in the region of the Tonga Subduction Zone. Geophys. Res. Letts., 28(9),1855-1858. 
Jaffe, J.S., P.J.S. Franks and A.W. Leising, 1998: Simultaneous imaging of phytoplankton and zooplankton distributions. Oceanography, 11(1), 24-29.

Jensen. F., W.A. Kuperman, M.B. Porter, H. Schmidt, 1993: Computational Ocean Acoustics. AIP Press, Springer-Verlag, New York, 578 pp.

Kuperman, W.A., W.S. Hodgkiss, H.C. Song, T. Akal, C. Ferla and D.R. Jackson, 1998: Phase conjugation in the ocean: Experimental demonstration of an acoustic time reversal mirror. J. Acoust. Soc. Am., 103(1), 25-40.

Lonsdale, P., 1994: Structural geomorphology of the Eltanin fault system and adjacenttransform faults of the Pacific-Antarctic plate boundary. Mar. Geophys. Res., 16,105-143.

Lonsdale, P., 1995: Segmentation and disruption of the East Pacific Rise in the mouth of the Gulf of California. Mar. Geophys. Res., 17, 323-359.

Mason, R.G. and A.D. Raff, 1961: Magnetic survey off the west coast of the United States between $32^{\circ} \mathrm{N}$ latitude and $42^{\circ} \mathrm{N}$ latitude. Bull. Geol. Soc. Am., 72, 1259-1266.

McDonald, M.A., J.A. Hildebrand and S.C. Webb, 1995: Blue and fin whales observed on a seafloor array in the Northeast Pacific. J. Acoust. Soc. Am., 98(2), 712-721.

Melville, W.K., 1996: The role of surface-wave breaking in air-sea interaction. Annual Rev. of Fluid Mech., 28, 279-321.

Melville, W.K. and P. Matusov, 2002. Distribution of breaking waves at the ocean surface. Nature, 417, 58-63.

Pinkel, R., 2000: Internal solitary waves in the warm pool of the western equatorial Pacific. J. Phys. Oceanogr., 30, 2906-2926.

Pinkel, R. and J.A. Smith. 1992: Repeat-sequence coding for improved precision of Dopplersonar and sodar. J. Atmos. and Oceanic Tech., 9(2), 149-163.

Raff, A.D. and R.G. Mason, 1961: Magnetic survey off the west coast of the United States between $40^{\circ} \mathrm{N}$ latitude and $52^{\circ} \mathrm{N}$ latitude. Bull. Geol. Soc. Am., 72, 1267-1270.

Smith, D., A. Wiens, K.M. Fischer, L.M. Dorman, S.C. Webb and J.A. Hildebrand, 2001:A complex pattern of mantle flow in the lau backarc. Science, 292, 713-716.

Smith, J.A., 1998: Evolution of Langmuir circulation during a storm. J. Geophys. Res., 103(C6), $12,649-12,668$.

Smith, J.A. and J.L. Largier, 1995: Observations of nearshore circulation-Rip currents. J.Geophys. Res., 100(C6), 10,967-10975.

Sohn, R.A., J.A. Hildebrand and S.C. Webb, 1999: A microearthquake survey of the high-temperature vent fields on the volcanically active East Pacific Rise 9Ú 50’N. J. Geophys.Res. 104, 25,367-25,377.
Song, H.C., W.A. Kuperman and W.S. Hodgkiss, 1998: A time reversal mirror with variable range focusing. JASA, 103(6), 3234-3240.

Song, H.C., W.A. Kuperman, W.S. Hodgkiss, P. Gerstoft and J.S. Kim, 2003: Null broadening with snapshotdeficient covariance matrices in passive sonar. IEEE J. Oceanic Engin., 28(2), April.

Spiess, F.N., M.S. Loughridge, M.S. McGehee and D.E. Boegeman, 1966: An acoustic transponder system. J. Inst. Navig., 13(2), 154-161.

Spiess, F.N. and R. C. Tyce, 1973. MPL DEEP TOW instrumentation system. [Reference 73-4,37 pp, Scripps Institution of Oceanography, UCSD].

Stemlicht, D.D. and C.P. de Moustier, 2002: Near bottom sediment characterization offshore SanClemente Island. Oceans' '02 MTS/IEEE, Volume 4, October 29-31.

Stokes, M.D., G. Deane, M. Latz and J. Rohr, in press. Bioluminescence imaging of wave induced turbulence. J. Geophy. Res.-Ocean.

Stokes, M.D., G. Deane, S. Vagel and D. Farmer, 2002: Measurements of large bubbles in open-ocean whitecaps. Geophys. Mono., 127, 270-285.

Stramski, D., R.A. Reynolds, M. Kahru and B.G. Mitchell, 1999: Estimation of particulate organic carbon in the ocean from satellite remote sensing. Science, 285, 239-242.

Stramski, D., A. Bricaud and A. Morel, 2001: Modeling the inherent optical properties of the ocean based on the detailed composition of planktonic community. Applied Optics, 40, 2929-2945.

Terrill, E.J., 2002: Designing coastal observatories to address local water quality needs. In: Proceedings of California and the Worlds Oceans Conference, Santa Barbara, CA.

Terrill, E.J., W.K. Melville, D. Stramski, 2001: Bubble enterainment by breaking waves and their influence on optical scattering in the upper ocean. $J$. Geophys. Res., 106(C8),16,815-16,823.

Thode, A.M., G. L. D'Spain, W.A. Kuperman, 2000: Matched-Field processing, source signature recovery, and geoacoustic inversion of blue whale vocalizations. J. Acous. Soc. America, 107(3), 1286-1300.

Thode, A.M., D.K. Mellinger, S. Stienessen, A. Martinez, K.D. Mullin, submitted: Depth-dependent behavioral and spectral features of diving sperm whales in the Gulf of Mexico. J. Acous. Soc. Am.

Vacquier, V., 1945: The Gulf absolute magnetometer. Terr. Magn. Atmo. Elec., 50, 91-104.

Webb, S.C. (1998). Broadband seismology and noise under the ocean. Rev. of Geophysics, 36,105-142.

Wiggins, S., in press: Autonomous Acoustic Recording Packages (ARPs) for long-term monitoring of whale sounds. Mar. Tech. Soc. J. 